\title{
Technical Efficiency of Banking institutions in a Pacific Island Country: A Distance Function Stochastic Frontier Analysis ${ }^{\#}$
}

\author{
Parmendra Sharma ${ }^{a, b *}$, Savaira Manoa ${ }^{c}$, Seci Taleniwesi ${ }^{c}$, and \\ Son Nghiem $^{d}$ \\ ${ }^{a}$ Department of Accounting, Finance and Economics, Griffith University \\ ${ }^{b}$ Griffith Asia Institute, Griffith University \\ ${ }^{c}$ Reserve Bank of Fiji \\ ${ }^{d}$ Australian Research Centre for Health Services Innovation, \\ Queensland University of Technology
}

\begin{abstract}
This is the first study, to our knowledge, that estimates the technical efficiencies, and total factor productivity growth and its components, using a distance function stochastic frontier approach and three single-output models in Fiji, a Pacific Island Country - a region where banking efficiency literature remains scarce despite phenomenal advances in the field. This study's ability to discuss the implications of the results for individual institutions separately is a key contribution of efficiency studies relating to the region as well as to the extant literature. The study found that there is substantial scope for improvement of productivity and efficiency, especially in producing more deposits with the same level of inputs.
\end{abstract}

Keywords: Distance function SFA, technical efficiency, total factor productivity, banks, Fiji, Pacific Island Countries (PICs)

\footnotetext{
\#Views and opinions expressed in this paper are those of the authors and do not reflect those of the Reserve Bank of Fiji or its Board. Only published data has been used in the analysis - available from the Reserve Bank of Fiji web site. This paper is an outcome of the 2015 Australian Government's Department of Foreign Affairs and Trade funded Australian Awards Fellowship program involving research training of RBF Fellows at Griffith University. The paper is also part of the on-going RBF-Griffith research initiatives commenced in 2014.

* Corresponding author: p.sharma@griffith.edu.au; +61 0737357834
} 


\section{$1.0 \quad$ Introduction}

Banking efficiency and productivity studies have proliferated immensely since the 1960's, with the introduction of the X-efficiency concept by Leibenstein (1966). Research has since spanned many regions and countries - from the US to Latin America, South Africa, Asia and Europe (see e.g., Berger and Humphrey, 1997). Methods too have been extensively advanced and refined - the pioneer frontier analysis approach has expanded into two separate branches: parametric and non-parametric, with the former now including stochastic frontier analysis (SFA), thick frontier analysis (TFA) and distribution free analysis (DFA), and the latter, data envelopment analysis (DEA) and free disposal hull (FDH). Input-output specifications have similarly been transformed - for example, the deposit variable is now used as an input, output or even an intermediate product.

The foregoing depth and intensity of investigations indicate that our understanding of banking efficiency in different settings and environments has improved substantially. Important gaps and questions remain, nonetheless. A noticeable gap relates to bank efficiency in Pacific Island Countries (PICs) — efficiency of banks in these small island developing states is only beginning to be studied. And yet, these small, remote, vulnerable and isolated 'countries with special needs' and virtually non-existent financial markets are predominantly dependent on banks for constantly pressing economic growth and poverty alleviation needs. It gets worse-systemic bank instability in the region could be socio-economically disastrous-rescue plans are virtually non-existent and countries lack capacity to deal with such situations, including bailouts. Bearing the foregoinig in mind, together with a keen interest of the relevant regulator, the Reserve Bank of Fiji ${ }^{1}$, this study examines the efficiency and total factor productivity of banks in Fiji.

For a population of less than one million, scattered across more than 300 islands, Fiji has a relatively diverse financial system, made up of commercial banks, insurance companies, credit institutions, a housing authority, a development bank, unit trusts, credit unions, financial cooperatives, microfinance institutions, and others (Sharma and Gounder, 2015). Reforms too have been extensive, including the adoption of several BIS proposed guidelines such as capital adequacy, loan classifications, liquidity management, as well as substantial revision of the banking act (Sharma et al., 2013). In addition to the socio-economic characteristics of PICs

\footnotetext{
${ }^{1}$ Griffith University and the Reserve Bank of Fiji have jointly been writing policy research papers. The topics are usually nominated by Reserve Bank of Fiji.
} 
mentioend above, a series of miliatary coup d'état coupled on hand and a rich banking history dating back to 1873 and the constant presence of foreign banks, dominated by Australian, on the other, makes the Fijian study interesting.

Previous limited studies on PICs (Sharma et al., 2015) have used Data Envelopment Analysis (DEA) to estimate efficiencies - this study, for the first time, estimates technical efficiencies, total factor productivity growth and its components, using a stochastic distance function approach, which accommodates random noises and allows us to estimate technical efficiencies with multiple output settings. This is the first study to also examine the effects of the Global Financial Crisis (GFC) on the operational performance of banking institutions. Third, previous studies have focused on singple output models - this study uses multiple output using distance function stochastic frontier analysis. Further, this study discusses the implications of the results for each individual institution separately, which most of the existing efficiency studies spanning the vast number of countries and regions has not been able to do. This we believe is a key contribution of efficiency studies relating to the PICs as well as to the extant literature.

Results confirm the findings of previous studies that there is substantial scope for improvement, especially in the case of producing more deposits with the same level of inputs. However, the implications may not necessarily apply equivalently to all banking institutions-some institutions require far much more improvement than others-in the case of some, improvements of as much as $80 \%$ is feasible. If indeed more efficient banks are deemed to supply greater amounts of intermediated funds at more affordable prices, and at the same time remain profitable, safe and sound, then in light of the foregoing, a policy review appears imminent. Implications also apply more widely to the PIC region where similar banks operate under more or less similar market conditions.

The rest of the paper is organised as follows. Section 2 provides a brief review of the related literature. Section 3 outlines the methodology and data. Section 4 presents the overall empirical results. Section 5 discusses the implications of the results for individual institutions. Section 6 concludes.

\subsection{Literature on banking efficiency in developing countries}

The literature of banking efficiency is vast, covering numerous countries and regions; for the purposes of our study, we focus on reviewing studies of similar context to ours i.e. Asia-Pacific 
countries. A study by Sharma et. al. (2015), using DEA, show that efficiency levels of bank in Fiji may be slightly less than in Australia - the country of incorporation for the major banks, making up at least $70 \%$ of the banking sector. Moreover, larger banks may be less efficient than their smaller counterparts. Lin, Doan, and Doong (2016) investigate the effect of changes in bank ownership on cost efficiency across 12 Asian developing economies. Over the period of 2003-2012, foreign presence improves bank efficiency, mostly in countries with higher financial freedom. Moreover, increased government (domestic) ownership of bank appears to improve (impede) bank efficiency in countries with more financial freedom after GFC.

Nguyen (2018) examines the impact of diversification on cost and profit efficiency of commercial banks from six ASEAN countries from 2007-2014. The results suggest that more income-diversified banks have lower cost efficiency, while more asset-diversified banks have only lower persistent cost efficiency. More funding-diversified banks have higher profit efficiency, whereas more asset-diversified banks enjoy only higher persistent profit efficiency. Funding-diversified banks with majority government ownership demonstrate higher cost efficiency but lower profit efficiency than other banks, while both funding and asset diversification make foreign banks less profit efficient.

Sun and Chang (2011) examine the role of risk in determining the cost efficiency of international banks in eight emerging Asian markets. This study considers 8 risk measures covering credit risk, operational risk and market risk. The results indicate that risk measures represent significant effect on both level and variability of bank efficiency, and these effects are time and region dependant. Meslier, Tacneng, and Tarazi (2014) investigate the impact of bank revenue diversification on the performance of banks in the Philippines. The results show that, contrary to western economies, a shift toward non-interest activities increase bank profits and risk adjusted profits when banks are more involved in trading in government securities and have less exposure to SMEs. Foreign banks benefit more from such a shift.

Kamarudin, Sufian, and Nassir (2016) study the impact of GFC on profit efficiency level in 31 commercial banks in Bangladesh over 2004-2011, using a slack-based data envelopment analysis method. Moreover, multivariate panel regression analysis is used to examine the determinants of bank profit efficiency. They separate banks into state-owned commercial banks, private commercial banks and other banks. Findings reveal that relationship of size of bank, liquidity, economic growth and market concentration are significantly negative with 
profit efficiency of SCBs but positive to PCBs. Moreover, capitalization, credit risk and inflation are significant with positive and negative signs only to the efficiency of SCBs over the period of post GFC. Thi My Phan, Daly, and Akhter (2016) study the relationships between market concentration, bank competition and X-efficiency in banks across six Asian emerging countries-Bangladesh, India, Indonesia, Malaysia, Vietnam and Philippines-over the period of 2005-2012. Market concentration has a positive impact on X-efficiency, so does bank size and GDP growth rate. However, liquidity risk shows negative relation with X-efficiency.

Sathye (2003) investigates the productive efficiency of banks in India, using data envelopment analysis, for three groups of banks - publicly owned, privately owned and foreign owned. The results show that the mean efficiency score of Indian banks compares well with the world mean efficiency score and the efficiency of private sector commercial banks as a group is, paradoxically lower than that of public sector banks and foreign banks in India. Fujii, Managi, and Matousek (2014) aim to explore the technical efficiency and productivity growth in the Indian banking sector over the period of 2004-2011, using a weighted Russell directional distance model to measure technical inefficiency. A modified model is developed to measure TFP changes with non-performing loans. Significant inefficiency levels are observed among three ownership structure of banks. Foreign banks pull the production frontier into a more efficient direction with their strong market positions. SPBs and domestic private banks appear to have considerably higher inefficiencies. The results suggest the restructuring policy applied in late 1990s and early 2000s in India failed to impose a long-lasting effect.

Sanyal and Shankar (2011) investigate the impacts that ownership and competition have on the Indian bank productivity since 1991 reforms. They find that Indian private banks dominate the public and foreign banks in terms of productivity levels and growth. Apart from old Indian private banks, competition adversely impacts the productivity of all other banks, of which new Indian private banks are hit the most. The similarity can be observed for productivity growth. The post-1998 period exhibits a larger productivity gap between Indian private banks and public and foreign banks. Indian private bank productivity and productivity growth experienced severe downturn in the post-1998 period due to increasing competition.

Gulati and Kumar (2016) attempt to gauge the impact of GFC on bank efficiency in India, focusing on the evolution of profit efficiency before, during and after the crisis. This study employs a DEA-based meta profit frontier framework that takes into account technological 
heterogeneity across groups. The results show that profit efficiency declined mildly during the crisis and subsequently recovered. The ownership of banks leads to different impact by GFC, with new private banks experienced the largest drag in profit during crisis year. Foreign banks appear to be the technology leaders. Overall, no long-lasting adverse effect of GFC on profit efficiency existed in India due to adoption of accommodative macro policies aiming to inject sufficient liquidity.

Xiaogang, Skully, and Brown (2005) examine the cost, technical and allocative efficiency of 43 Chinese banks over the period of 1993-2000. The study sheds lights on the post-deregulation bank efficiency since 1995. They find that large state-owned and smaller banks are more efficient than medium sized Chinese banks. Moreover, technical efficiency consistently dominates the allocative efficiency among Chinese banks. Deregulation is found to improve cost efficiency levels. Barros, Chen, Liang, and Peypoch (2011) apply an innovative DEA model, the inverse B-convex model, to investigate the technical efficiency of a sample of Chinese banks from 1998 to 2008. The influence of firm size and ownership on bank efficiency is not presented. The overall efficiency has improved after China joined WTO.

Wang, Huang, $\mathrm{Wu}$, and Liu (2014) exploit a two-stage network DEA to evaluate 16 Chinese banks over the period of 2003-2011 (the third round of Chinese banking reform). The results suggest that reforms generally improve banking efficiency; state-owned banks are more efficient than joint-stock commercial banks in pre-reform period, while the difference has reduced during post-reform period; and the disposal of non-performing loans explains the efficiency improvement, and joint-equity reform of state-owned banks increased efficiencies.

In summary, while numerous studies examine the efficiency of commercial banks in the AsiaPacific region, to our best knowledge, there is a lack of studies on Pacific Island countries. Also, few previous studies have applied stochastic distance function in their analyses.

\subsection{Data and methodology}

\section{Data}

Our sample includes four of the six commercial banks operating in Fiji in 2014, namely, Australia and New Zealand Banking Corporation Ltd (ANZ); Bank of Baroda (BOB); Bank South Pacific Limited (BSP); and Westpac Banking Corporation Limited (WBC). BRED Bank 
Fiji Ltd (BRED) is not included in the sample - essentially for the reason thatit is fairly new, having commenced operations in 2014. Home Finance Company Bank (HFC), which obtained a commercial banking licence in 2013 is included as a credit institution since, for the large part of the sample period, it had operated as a credit institution. Technical efficiencies of banks are compared with that of credit institutions, which include Credit Corporation Fiji Limited (CCFL); Merchant Finance Limited (MF); and Home Finance Company Limited (HFC). CIs are a smaller version of commercial banks, allowed to provide most banking services but not permitted to provide demand deposits, and term deposits must not be less than F\$10,000 in value. Relevant and complete Fiji operations data for these institutions are available on-line for the years 1999-2014 from the RBF website.

\section{Input-output variables}

In the banking efficiency literature, two main approaches define the input-output variable selection: intermediation and production (e.g. Berger \& Humphrey, 1997). This study adopts the "production" approach, which views financial institutions as 'producers' of services for account holders, and specifies deposits as an output (see Table 1). The other outputs include: net profit before tax, and interest and similar revenues (proxy for total revenues). The inputs include: interest and similar expenses, general expense (proxy for labour) and capital. To control for heterogeneity, this study employs four environmental factors - capital adequacy ratio, liquid assets, institution type (dummy, 1 = commercial banks; 0 otherwise) and the global financial crisis (GFC) (dummy, 1=2008 and later; zero otherwise).

The descriptive statistics in Table 1 show that general expense (used as proxy for labour) is the largest input with an average of FJD17,699, followed by capital with the mean of FJD12,620 and interest expenses with the average of FJD7,848. With respect to outputs, deposits was the largest output with an average of FJD416,803, followed by revenue and profits with the means of FJD28,886 and FJD17,290, respectively. With respect to environmental factors, capital adequacy ratio had a mean value of $18.85 \%$ and the average liquid assets was FJD137,663.

\section{[Table 1]}




\section{Methodology}

The Distance Stochastic Frontier Analysis (SFA)

As with the input - output selection, two methodologies have also dominated the literature investigating efficiency and productivity in the banking sector: the non-parametric DEA and the parametric SFA. This study uses the SFA approach, which is able to accommodate random noises but not able to take into account multiple outputs. To address this, we use the distance function SFA, which allows us to estimate technical efficiencies with multiple output settings.

The concept of the distance function was first proposed by Malmquist (1953), but Farrell (1957) pioneered its application to estimating efficiency. Essentially, the distance function measures the distance between observed input-output combinations to ideal input-output combinations on the efficiency frontier. Thus, letting $x \in R_{+}^{K}$ be the vector of inputs, and $y \in R_{+}^{M}$ the vector of outputs, for a given technology $T$ then, the production possibility set of a firm at period $t$ may be defined as:

$$
T^{t}=\{(x, y): x \text { can produce } y \text { in period } t\}
$$

A distance function can be measured either by focusing on inputs (the minimization of inputs while producing a given level of outputs) or outputs (maximizing output from a given combination of inputs). Thus, an output distance function $\left(\mathrm{D}_{\mathrm{O}}\right)$ at period $t$ of a firm can be defined as a production possibility set with given input quantity, the output level can be expanded by $1 / \theta(0<\theta<1):^{2}$

$$
D_{O}^{t}\left(x^{t}, y^{t}\right)=\operatorname{Min}_{\theta}\left\{\left(x^{t}, \frac{y^{t}}{\theta} \in T\right)\right\}
$$

To measure the changes in efficiency between periods, Caves et al. (1982) introduced the Malmquist productivity index (MPI), which is the ratio of the distance function using inputs and outputs from different periods. The MPI of periods $t$ and $t+1$ can be defined as:

$$
M P I^{t}=\frac{D^{t}\left(x^{t+1}, y^{t+1}\right)}{D^{t}\left(x^{t}, y^{t}\right)} ; M P I^{t+1}=\frac{D^{t+1}\left(x^{t+1}, y^{t+1}\right)}{D^{t+1}\left(x^{t}, y^{t}\right)}
$$

Färe et al. (1992) proposed that changes in the MPI between the two periods are the geometric means of MPIs, which can be decomposed into two components: shifts of the frontier, which

\footnotetext{
${ }^{2}$ An input distance function is represented in a similar manner. For more details, see for example, Coelli et al. (2005)
} 
are attributable to technological progress, and movement towards the frontier, which are attributable to improvements in technical efficiency, respectively.

$$
\begin{aligned}
M P I^{t, t+1} & =\sqrt{\frac{D^{t}\left(x^{t+1}, y^{t+1}\right)}{D^{t}\left(x^{t}, y^{t}\right)} \times \frac{D^{t+1}\left(x^{t+1}, y^{t+1}\right)}{D^{t+1}\left(x^{t}, y^{t}\right)}} \\
& =\frac{D^{t+1}\left(x^{t+1}, y^{t+1}\right)}{D^{t}\left(x^{t}, y^{t}\right)} \times \sqrt{\frac{D^{t}\left(x^{t+1}, y^{t+1}\right)}{D^{t+1}\left(x^{t+1}, y^{t+1}\right)} \times \frac{D^{t}\left(x^{t}, y^{t}\right)}{D^{t+1}\left(x^{t}, y^{t}\right)}}
\end{aligned}
$$

The SFA method requires an assumption about the functional form of the production functions (Cobb-Douglas or trans-logarithmic functions). In this study, we use the trans-logarithmic (translog) functional form because it can mimic an impressive degree of flexibility (Berndt, 1991). Assuming that technological progress is represented by the time trend $t$, the output distance function of bank $i$ with $K$ inputs and $M$ outputs under the assumption of the translog functional form may be expressed as:

$$
\begin{aligned}
\log \left(D_{O i}\right) & =\alpha_{0}+\sum_{m=1}^{M} \alpha_{m} \log \left(y_{m i}\right)+\sum_{k=1}^{K} \beta_{k} \log \left(x_{k i}\right)+\frac{1}{2} \sum_{m=1}^{M} \sum_{n=1}^{M} \alpha_{m n} \log \left(y_{m i}\right) \times \log \left(y_{n i}\right) \\
& +\frac{1}{2} \sum_{k=1}^{K} \sum_{l=1}^{K} \beta_{k l} \log \left(x_{k i}\right) \times \log \left(x_{l i}\right)+\sum_{k=1}^{K} \sum_{m=1}^{M} \delta_{k m} \log \left(x_{k i}\right) \times \log \left(y_{m i}\right) \\
& +\sum_{m=1}^{M} \gamma_{m} \log \left(y_{m i}\right) \times t+\sum_{k=1}^{K} \eta_{k} \log \left(x_{k i}\right) \times t+\delta_{1} \log (t)+\delta_{1}(\log (t))^{2}+\varepsilon_{i}
\end{aligned}
$$

where $\varepsilon$ is the random error and the functional form satisfies the constraint for homogeneity of degree one in outputs, and the constraint of symmetry.

Unfortunately, the distance function is not observed, thus Equation 5 cannot be estimated as is. In the case of a single output, one can estimate Equation 5 by rearranging the distance function on the right-hand-side, and applying a standard SFA approach to decompose the composite error term $\left(\varepsilon_{i}-\log \left(D_{O i}\right)\right)$ into a random error component $\varepsilon_{i}$, and an inefficiency component $\log \left(D_{O i}\right)$, which is assumed to follow a non-negative distribution. In case of multiple outputs, we can apply the method proposed by Coelli and Perelman (2000), which exploits the homogeneity of degree one in outputs, selecting arbitrarily one output (for example, $Y_{M i}$ ) as the numeraire. Recall that a function with homogeneity of degree $\omega$ is defined as:

$$
D_{O}(x, \omega y)=\omega D_{O}(x, y) \quad \text { for } \omega>0(6)
$$

Defining one output arbitrarily as a numeraire $\left(\omega=\frac{1}{y_{M i}}\right)$ this transformation can be expressed as: 


$$
D_{O}\left(X, Y / y_{M i}\right)=D_{O}(X, Y) / y_{M i}
$$

Applying this to the translog distance function in Equation 5, we can transform it to a SFA specification, as follows:

$$
\begin{aligned}
-\log \left(y_{M i}\right) & =\alpha_{0}+\sum_{m \# M} \alpha_{m} \log \left(y_{m i} / y_{M i}\right)+\sum_{k=1}^{K} \beta_{k} \log \left(x_{k i}\right) \\
& +\frac{1}{2} \sum_{m \# M n \# M} \sum_{m n} \log \left(y_{m i} / y_{M i}\right) \times \log \left(y_{n i} / y_{M i}\right) \\
+ & \frac{1}{2} \sum_{k=1}^{K} \sum_{l=1}^{K} \beta_{k l} \log \left(x_{k i}\right) \times \log \left(x_{l i}\right)+\sum_{k=1}^{K} \sum_{m \# M} \delta_{k m} \log \left(x_{k i}\right) \times \log \left(y_{m i} / y_{M i}\right) \\
+ & \sum_{m \# M} \gamma_{m} \log \left(y_{m i} / y_{M i}\right) \times t+\sum_{k=1}^{K} \eta_{k} \log \left(x_{k i}\right) \times t+\delta_{1} \log (t) \\
+ & \delta_{1}(\log (t))^{2}+\varepsilon-\log \left(D_{O i}\right)
\end{aligned}
$$

Efficiency changes can then be estimated from Equation 8 as the ratio of the efficiency score between the current and the reference periods while technological changes are measured as the average of the time derivatives between periods. To take into account effects of the operational environment, we apply the technical efficiency effects model by Battese and Coelli (1995), which specifies that $m_{i}=z_{i} \sigma$ where $m_{i}$ is the mean of the inefficiency component $\log \left(D_{O i}\right)$ and $z_{i}$ is the vector of environmental variables. This procedure produces more consistent estimates than the second-stage regression approach (Coelli, 1996).

Under this specification, technical efficiency (TE) scores are defined as the exponentiation of the distance function:

$$
T E_{i}=\exp \left[-\log \left(D_{O i}\right)\right]
$$

Efficiency changes (EC) are defined as the ratio of efficiency scores between two periods:

$$
E C=\frac{T E_{t+1}}{T E_{t}}
$$

Technical changes (TC) are defined as geometric means of the time derivatives between two periods:

$$
T C=\exp \left\{\frac{1}{2} \times\left[\frac{\delta \log \left(y_{M i, t+1}\right)}{\delta_{t+1}}+\frac{\delta \log \left(y_{M i, t}\right)}{\delta_{t}}\right]\right\}
$$


TFP changes (TFPC) is the product of efficiency changes and technical changes $(T F P C=E C \times T C)$. One can also calculate scale changes (SC) as the geometric means of scale efficiency between two periods:

$$
S C=\exp \left\{\frac{1}{2} \times \log \left(\frac{x_{n i, t+1}}{x_{n i, t}}\right) \times \sum_{n=1}^{N}\left[\varepsilon_{n i, t} S F_{i, t}+\varepsilon_{n i, t+1} S F_{i, t+1}\right]\right\}
$$

where $S F_{i t}=\left(\varepsilon_{i t}-1\right) / \varepsilon_{n i, t} ; \varepsilon_{i t}=\sum_{n=1}^{N} \varepsilon_{n i, t} ;$ and $\varepsilon_{n i, t}=\frac{\delta \log \left(y_{M i, t}\right)}{\delta \log \left(x_{n i, t}\right)}$.

Overall, the distance function SFA adopts the advantages of both non-parametric approach (i.e. able to take into account multiple outputs, and does not require behavioural assumptions) and parametric approaches (i.e. able to take into account effects of random noises). In the case when panel data is available, such as ours, this approach is able to estimate total factor productivity growth and its components, i.e. efficiency changes, technological progress and scale changes.

\subsection{Empirical results}

Recall that our selected inputs are interest expenses, general expense (proxy for labour) and capital, and outputs include net profit before tax, and interest revenues (proxy for total revenues) plus deposits as a numeraire. Since profit and revenue are often highly correlated despite measuring slightly different aspects of operational performance, we decided to use profit and revenue in two separate models. The first model includes two outputs: profit and deposit, while the second model includes revenue and deposit as outputs. We use Akaeke Information Criteria (AIC) and Bayesian Information Criteria (BIC) to select the preferred model. The results show that Model 1 has lower AIC and BIC, and hence is preferred (see Table 2).

\section{[Table 2]}

To control for heterogeneity, four environmental factors - capital adequacy ratio, liquid assets, institution type and the global financial crisis (GFC) are used. The main disadvantage with this transformation is that some parameters are difficult to interpret. For example, parameter of $1 \mathrm{x} 1$ can only be interpreted as one percent increase in the interest expense/deposit ratio is associated with 0.84 percent increase in deposit (Table 2, Model 1). 
The time trend parameter $(t)$ shows that the operational efficiency of Fiji's banking institutions declined by 0.1 percent per year. We standardise (convert the variable to get a mean of zero and standard deviation of one) the continuous environmental variables (capital adequacy ratio and liquid asset) for ease of interpretation. In particular, an increase in capital adequacy ratio by one standard deviation is associated with an improvement in operational efficiency of financial institutions by 0.11 percent. The negative sign of the liquid asset parameter seems counter-intuitive: those with more liquid assets are less efficient. One possible explanation is that liquid assets may produce lower returns than non-liquid assets. The positive sign of the global financial crisis (GFC) parameter also seems counter-intuitive but it is not significant. Technological progress may offset the short-term effects of the GFC. It is also possible that banking institutions in Fiji have had less exposure to global financial markets compared to institutions in other parts of the world. The parameters of $\delta_{\mathrm{U}}$ and $\delta_{\mathrm{V}}$ reveal that the inefficiency component is clearly present in the composite error term. The substantial magnitude of the signal-to-noise ratio $(\lambda)$ of 104.3 also confirms that the variation in outputs of institutions is more than likely to be due to inefficiency rather than random noise.

As we turn our attention to total factor productivity (TFPC), we find that, over the sample period of 2000 to 2014, the average annual growth was 12.66 percent (Table 3); contributed mostly by technological changes (TC, 10.4 percent), followed by technical efficiency changes (TEC, 2.55 percent) - scale changes (SC) were inconsequential. As the table also shows, negative TPFCs were recorded for 2000 and 2009, due possibly to the political disturbance (coup d'état) and the GFC, respectively. The average technical efficiency score was relatively low at 0.42 , suggesting that an average bank can improve profit by $58 \%$ using the same expense and capital if they can follow the best practices.

\section{[Table 3]}

The big two - ANZ and WBC_-95\% and 77\%, respectively, lead the performance in technical efficiency (Table 4). Of the other banking institutions, BOB is the better performer- $-73 \%$. On the other hand, all of the other banking institutions, including the region's largest home bank, BSP, have shown considerably low TE performance. In some cases, the extent of improvement is more than $90 \%$. In these cases, the overall change in TE (TEC) had actually reversed. A 
decline scale efficiency is also noted in the case of a number of institutions. Nevertheless, the change in total factor productivity (TFPC) is positive for all institutions.

\section{[Table 4]}

\subsection{What do the results mean for individual institutions?}

Figure 3 shows the profit efficiency of individual banking institutions over the sample period. ANZ appears to have been consistently the most "profit" efficient bank in the industry, with efficiency averaging $95 \%$ over the period and never drop to $80 \%$ except in 2000 . The trends indicate that ANZ might be on track to remain highly efficient in the coming years. The next most consistently efficient institution in the industry appears to have been WBC and $\mathrm{BOB}$ despite their performance fluctuate much more than ANZ. Like ANZ, BOB and WBC exhibit signs of reaching full potential in coming years.

\section{[Figure 3]}

Among all of the remaining institutions, especially HFC, MFIL and CCFL contributed considerably to the overall low profit efficiency of the industry over the sample period with the average efficiency around $10 \%$. In this sense, these banks would also get the attention of the regulator and industry. One may argue that these are small scale banks and they have more room to improve operational efficiency by increasing scale. However, this scenario may be the case only for CCFL, which has the most substantial scale growth of 2.33 per cent per year.

\subsection{Conclusion}

Despite the depth and intensity of investigations and studies on banking efficiency, spanning many years,countries, regions, methods and techniques, gaps and questions remain. One noticeable gap relates to banking efficiency in the small, vulnerable, isolated, Pacific Island Countries (PICs) where economic growth and poverty alleviation remains a constant and increasingly alarming challenge and where the literature endorsed finance-led growth and development is virtually bank-dependent. On a positive note, this apparent gap in the literature is now being gradually abridged but more studies are needed for robustness and better-informed policy development and formulation. This is precisely the purpose of the present study. 
The present study provides fresh evidence using new techniques and an expanded time period. The present study is the first to estimate technical efficiencies (TE), total factor productivity (TFP) growth and its components, using a distance function stochastic frontier approach and three single-output models in in the case of a PIC. Moreover, it extends the time period to 2014, enabling for the first time to examine effects of the Global Financial Crisis (GFC) on the operational performance of banking institutions. Further, this study's ability to discuss the implications of the results of each individual institution separately is a key contribution of efficiency studies relating to the PICs as well as to the extant literature.

Results, using Fiji as a case study, confirm the findings of previous studies that there is substantial scope for improvement, especially in the case of producing more deposits with the same level of inputs. However, the implications may not necessarily apply equivalently to all banking institutions - some institutions require far much more improvement than others - in the case of some, improvements of as much as $80 \%$ is feasible. If indeed more efficient banks are deemed to supply greater amounts of intermediated funds at more affordable prices, and at the same time remain profitable, safe and sound, then in light of the foregoing, a policy review appears imminent. Implications also apply more widely to the PIC region where similar banks operate under more or less similar market conditions.

\section{References}

Aigner, D. J., C. A. K. Lovell, and P. Schmidt, 1977. Formulation and estimation of stochastic frontier production function models, Journal of Econometrics, 6, 21-37.

Battese, G. E., \& Coelli, T. J. (1995). A model for technical inefficiency effects in a stochastic frontier production function for panel data. Empirical economics, 20(2), $325-332$.

Barros, C. P., Chen, Z., Liang, Q. B., \& Peypoch, N. (2011). Technical efficiency in the Chinese banking sector. Economic Modelling, 28(5), 2083-2089.

Beck, T., Demirgüç-Kunt, A. and Peria M. (2007) Banking services for everyone? Barriers to bank access and use around the world, World Bank Economic Review, 22, 397-430.

Beck, T., Demirgüç-Kunt, A., \& Peria, M. S. M. (2008). Banking services for everyone? Barriers to bank access and use around the world. The World Bank Economic Review. 
Berger, A. N., \& Humphrey, D. B. (1997). Efficiency of financial institutions: International survey and directions for future research. European journal of operational research, 98(2), 175-212.

Berger, A.N., Hunter, W. C., and Timme, S. G. (1993) The efficiency of financial institutions:

a review and preview of research past, present and future, Journal of Banking and Finance, 17, 221-249.

Coelli, T. J. (1996). A guide to FRONTIER version 4.1: a computer program for stochastic frontier production and cost function estimation: CEPA working paper.

Coelli, T. J., Rao, D. S. P., O'Donnell, C. J., \& Battese, G. E. (2005). An introduction to efficiency and productivity analysis: Springer Science \& Business Media.

Coelli, T., \& Perelman, S. (2000). Technical efficiency of European railways: a distance function approach. Applied Economics, 32(15), 1967-1976.

Farrell, M. J. (1957). The measurement of productive efficiency. Journal of the Royal Statistical Society. Series A (General), 253-290.

Feng, G. and A. Serletis, 2010. Efficiency, technical change, and returns to scale in large US banks: Panel data from an output distance function satisfying theoretical regularity, Journal of Banking and Finance, 34, 127-138.

Fujii, H., Managi, S., \& Matousek, R. (2014). Indian bank efficiency and productivity changes with undesirable outputs: A disaggregated approach. Journal of Banking \& Finance, $38,41-50$.

Gulati, R., \& Kumar, S. (2016). Assessing the impact of the global financial crisis on the profit efficiency of Indian banks. Economic Modelling, 58, 167-181.

Hamit-Haggar, M. (2009). Total Factor Productivity growth, Technological Progress, and Efficiency Changes: Empirical Evidence from Canadian Manufacturing Industries: Department of Economics, University of Ottawa= Dép. de Science économique, Université d'Ottawa.

Jiang, C., Yao, S., \& Zhang, Z. (2009). The effects of governance changes on bank efficiency in China: a stochastic distance function approach. China Economic Review, 20(4), 717-731.

Kamarudin, F., Sufian, F., \& Nassir, A. M. (2016). Global financial crisis, ownership and bank profit efficiency in the Bangladesh's state owned and private commercial banks. Contaduría y Administración, 61(4), 705-745.

Kirkwood, J., \& Nahm, D. (2006). Australian banking efficiency and its relation to stock returns. Economic Record, 82(258), 253-267. 
Leibenstein, H. (1966). Allocative efficiency vs. "X-efficiency". American Economic Review, $56,392-415$.

Lin, K.-L., Doan, A. T., \& Doong, S.-C. (2016). Changes in ownership structure and bank efficiency in Asian developing countries: The role of financial freedom. International Review of Economics \& Finance, 43, 19-34.

Malmquist, S. (1953). Index numbers and indifference surfaces. Trabajos de Estadistica y de Investigacion Operativa, 4(2), 209-242.

Meslier, C., Tacneng, R., \& Tarazi, A. (2014). Is bank income diversification beneficial? Evidence from an emerging economy. Journal of International Financial Markets, Institutions and Money, 31, 97-126.

Nguyen, T. L. A. (2018). Diversification and bank efficiency in six ASEAN countries. Global Finance Journal, 37, 57-78.

PFTAC (Pacific Financial Technical Assistance Centre) (2011) Interest Rates and Bank Profitability in the South Pacific. Available at http://www.pftac.org/Handbooks/Governors\%20Paper.pdf (accessed November, 2011).

Sanyal, P., \& Shankar, R. (2011). Ownership, competition, and bank productivity: An analysis of Indian banking in the post-reform period. International Review of Economics \& Finance, 20(2), 225-247.

Sathye, M. (2003). Efficiency of banks in a developing economy: The case of India. European Journal of Operational Research 148, 662-671.

Sealey, C. W., \& Lindley, J. T. (1977). Inputs, outputs, and a theory of production and cost at depository financial institutions. The Journal of Finance, 32(4), 1251-1266.

Shamsuddin, A., \& Xiang, D. (2012). Does bank efficiency matter? Market value relevance of bank efficiency in Australia. Applied Economics, 44(27), 3563-3572.

Sharma, P. and N. Gounder, 2015. Resilient through the GFC and beyond: What drives bank profitability in small, open economies? Asia Pacific Journal of Business, 16(3), 191209.

Sharma, P., N. Gounder, and D. Xiang, 2013, Foreign banks, profits, market power and efficiency in PICs: some evidence from Fiji, Applied Financial Economics, 23(22), 1733-1744.

Sharma, P., Gounder, N., \& Xiang, D. (2015). Level and Determinants of Foreign Bank Efficiency in a Pacific Island Country. Review of Pacific Basin Financial Markets and Policies, 18(01), 1550005.

Shephard, R. W. (2012). Cost and production functions (Vol. 194): Springer Science \& Business Media. 
Sun, L., \& Chang, T.-P. (2011). A comprehensive analysis of the effects of risk measures on bank efficiency: Evidence from emerging Asian countries. Journal of Banking \& Finance, 35(7), 1727-1735.

Sturm, J.-E., \& Williams, B. (2004). Foreign bank entry, deregulation and bank efficiency: Lessons from the Australian experience. Journal of Banking \& Finance, 28(7), 17751799.

Thi My Phan, H., Daly, K., \& Akhter, S. (2016). Bank efficiency in emerging Asian countries. Research in International Business and Finance, 38, 517-530.

Wang, K., Huang, W., Wu, J., \& Liu, Y.-N. (2014). Efficiency measures of the Chinese commercial banking system using an additive two-stage DEA. Omega, 44, 5-20.

Xiaogang, C., Skully, M., \& Brown, K. (2005). Banking efficiency in China: Application of DEA to pre-and post-deregulation eras: 1993-2000. China Economic Review, 16(3), 229-245. 